\title{
Development of Experience Dance Game using Kinect Motion Capture
}

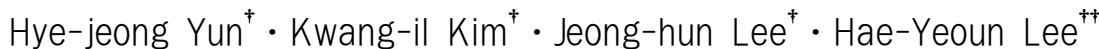

\begin{abstract}
Console game has high market occupancy in the world game market and has popular favor for many players. Especially, the experience console game in which body movement is used to control the game has made its own market. However, previous experience console games can easily make players to be boring and require additional payments to update the game. In this paper, we present an experience dance game using Kinet, which has high interest and can be continuously updated. Differently from previous console games, the presented game makes the player to see how they are playing and to know what the next action is. Also, the accuracy of the player motion is compared 20 times in each second to get high interests of players. Through these functions, the presented game can achieve high satisfaction rates based on the qualitative evaluation of users.
\end{abstract}

\section{Keywords : Kinect, Experience Game, Motion Capturing, Motion Matching}

\section{키넥트를 이용한 체감형 동작 인식 댄스 게임 개발 \\ 윤 혜 정 ${ }^{\dagger}$ 김 광 일 $^{\dagger} \cdot$ 이 정 훈 $^{\dagger} \cdot$ 이 해 연 ${ }^{+\dagger}$}

\begin{abstract}
요 약
세계 게임 시장에 있어서 콘솔 게임은 가장 높은 점유율을 차지하고 있고 많은 인기를 얻어왔다. 특히 조작을 위해 몸을 움직여서 동작하는 체감형 콘솔 게임은 독자적인 시장을 구축해왔다. 하지만, 기존 콘솔 게임 소프트웨어들은 쉽게 싫증을 느낄 수 있고, 높은 비용을 요구함으로 서 사용자에게 부담을 준다. 본 논문에서는 저렴하고 쉽게 싫증나지 않도록 지속적인 업데이트가 가능한 키넥트를 사용한 동작 인식 체감형 게 임을 개발하였고 이에 대하여 설명한다. 기존 콘솔 댄스 게임에서는 자신을 모습을 볼 수 없을 뿐만 아니라 지정한 동작만을 비교하는 반면에 본 논문에서 개발한 체감형 댄스 게임에서는 자신의 모습을 직접 확인 가능하며, 매 초 마다 20 회 정도 전체 동작을 비교해 높은 정확도와 흥 미를 부여한다. 이와 같은 기능을 제공함에 따라 사용자의 정성적인 평가에 따르면 개발한 시스템의 만족도가 높은 것으로 나타났다.
\end{abstract}

키워드 : 키넥트, 체감형 게임, 동작 인식, 동작 매칭

\section{1. 서 론}

세계 게임 시장에서 Fig. 1에 나타난 것과 같이 콘솔 게 임이 지속적으로 높은 점유율을 차지하고 있다[1,2]. 특히 사용자가 직접 컨트롤러가 되어 제어하는 체감형 콘솔 게임 은 닌텐도 사의 $\mathrm{Wii}$ 출시 이후로 소니 PlayStation Move, Microsoft X360 Kinect 등이 등장하며 많은 인기를 끌어왔 다[3, 4]. 하지만 별도의 컨트롤러와 외부 장치를 필요로 하 고 차별성을 부각시킨 콘텐츠의 확보 어려움으로 인하여 Wii는 하락세를 겪고 있다.

※ 이 논문은 제 40 회 추계학술발표대회에서 “키넥트를 이용한 동작 인식 댄 스 게임 개발”의 제목으로 발표된 논문을 확장한 것임.

※ 이 연구는 금오공과대학교학술연구비에 의하여 지원된 논문임

† 비 회 원 국립금오공과대학교 컴퓨터소프트웨어공학과 재학중

†† 정 회 원: 국립금오공과대학교 컴퓨터소프트웨어공학과 교수

논문접수 : 2013년 12월 2일

수 정 일 : 1차 2013년 12월 20일

심사완료 : 2013년 12월 20일

* Corresponding Author:Hae-Yeoun Lee(haeyeoun.lee@kumoh.ac.kr)

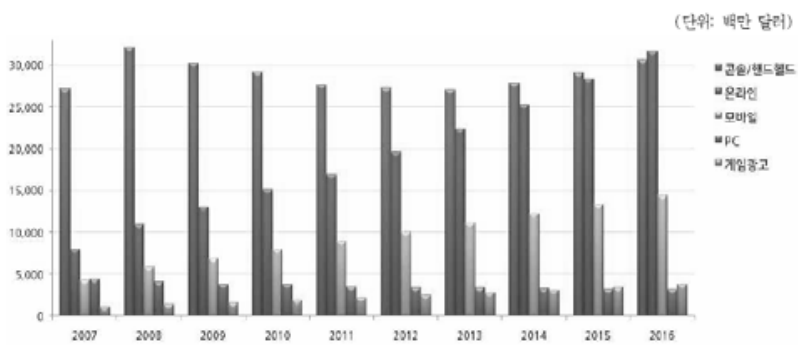

Fig. 1. World game market share and growth rate[1]

Microsoft 사는 Wii 메커니즘을 업그레이드하여 XBOX360 에 컨트롤러 단말 없이 온몸으로 조작할 수 있는 혁신적인 영상 인식 장치인 키넥트(Kinect)를 추가함으로써 체감형 콘 솔 게임 시장에 진입하였다. 이를 통하여 대부분 콘솔 게임 기 판매량이 감소하는 추세를 보임에도 불구하고 $\mathrm{XBOX} 360$ 
은 지속적으로 상승세를 보일 수 있었다[5].

키넥트는 총 3 개의 렌즈로 구성이 되어 있다. 중앙에 위 치한 RGB 인식 렌즈를 통하여 영상 촬영을 수행하며, 동시 에 적외선 렌즈를 통하여 적외선을 픽셀 단위로 투사한다. 깊이 인식 렌즈에서는 장면에 투사된 적외선 픽셀들을 촬영 하고 이를 통하여 대상의 깊이 연산을 가함으로 거리의 인 식과 사람의 골격을 인식할 수 있도록 제작된 장치이다.

하지만 닌텐도 Wii나 Microsoft XBOX360은 몇 가지 문 제점을 가지고 있다. Wii는 wii 리모콘이라는 동작인식 리모 콘을 가지고 사용자 동작을 인식하기 때문에 정확성이 떨어 지고 불편하다. 또한 게임 중 사용자가 자신의 모습을 확인 할 수 없다. XBOX360은 키넥트를 이용하여 동작 인식의 정 확성을 향상하였지만 $\mathrm{Wii}$ 와 마찬가지로 게임 진행 중 자신 의 모습을 확인 할 수 없다. 그리고 게임을 위해 게임기 본 체를 비롯하여 별도의 하드웨어를 필요로 하여 사용자로 하 여금 비용 부담을 요구한다. 마지막으로, 기존 체감형 게임 은 DVD형식으로 발매되어 구입 후 업데이트의 어려움이 따르며, 현재 일부 프로그램들은 인터넷의 연결을 통하여 업데이트가 가능하도록 개선이 되고 있다.

본 논문에서는 이와 같은 기존 콘솔 게임이 가지고 있는 문제를 해결한 체감형 댄스 게임 시스템을 제시한다. 먼저, 보급률이 높은 컴퓨터와 키넥트만을 이용하여 댄스 게임을 구현하여 비용 부담을 줄이고 컴퓨터 소프트웨어라는 특성 을 이용하여 업 데이트를 쉽게 한다. 또한, 키넥트로 사용자 의 동작을 인식하고, 사용자를 아바타화 하지 않고 실제 모 습을 보여줌으로써 사용자들에게 흥미를 유도한다. 실제 제 안하는 댄스 게임에 대한 사용자의 정성적인 평가에서도 높 은 만족도를 나타냈다.

본 논문의 구성은 다음과 같다. 2장에서 기존 체감형 콘 솔 게임을 살펴보고 3 장에서는 제안하는 게임 시스템에 대 하여 설명한다. 4 장에서 기존 체감형 콘솔 게임과 제안 게 임을 비교하고 분석한 후에 5장에서 결론을 도출한다.

\section{2. 관련 연구}

현재 게임 시장에서 Microsoft XBOX360의 키넥트 연동
Table 1. Representative experience console game products

\begin{tabular}{l|l|l}
\hline & Product & Kinect Sports Season2 \\
\cline { 2 - 3 } & Manufacturer & MS Game Studios \\
\cline { 2 - 3 } & Price & W45,000 \\
\hline & Product & Your Shape 2012 \\
\hline & Manufacturer & UBISOFT \\
\hline
\end{tabular}

게임과 닌텐도 $\mathrm{Wii}$ 의 게임이 높은 점유율을 차지하며 스테 디셀러로 자리 잡고 있다. Table 1은 현재 XBOX360의 키 넥트 연동 게임과 $\mathrm{Wii}$ 게임 중 대표적인 3 개의 제품명, 제 작사, 가격을 나열한 것이다.

소프트웨어 가격을 보면 소비자 게임 시장에서 고가에 해 당함을 알 수 있다. 또한 콘솔 게임의 소프트웨어는 DVD 형태로 판매하기 때문에 발매 후 업데이트가 거의 불가능하 며 Wii 본체 세트 또는 XBOX360과 키넥트를 동시에 소지 해야만 게임을 플레이 할 수 있다.

Fig. $2 \mathrm{a}$ 의 Just Dance2는 사용자가 노래를 선택하고 음악 을 들으면서 $\mathrm{NPC}(\mathrm{Non}-$ player character)의 동작을 따라하 는 댄스 게임이다[6]. 이 게임은 Wii 게임 특성상 wii 리모 콘을 이용하므로 특정 동작의 팔 움직임만을 인식한다. 이 는 사용자의 다른 부위 움직임과 전체 동작을 판별하는 것 이 수행되지 않음을 의미한다. 또한 게임 진행 중 자신의 모습을 확인 할 수 없어서 사용자는 자신의 동작과 $\mathrm{NPC}$ 의 동작을 비교할 수 없어 올바른 동작을 수행하기 힘들다. Fig. $2 \mathrm{~b}$ 의 유어쉐이프는 키넥트로 사용자의 모션을 캡쳐하 여 신체 동작을 인식하고, 신체 움직임을 게임에 반영하여 운동을 즐길 수 있는 게임이다. 사용자의 대략적인 모습을 보여주기도 하며, 틀린 부분이 있을 경우 지적이 이루어지 지만, 새로운 콘텐츠의 확장성 등에 있어서 어려움이 있다.

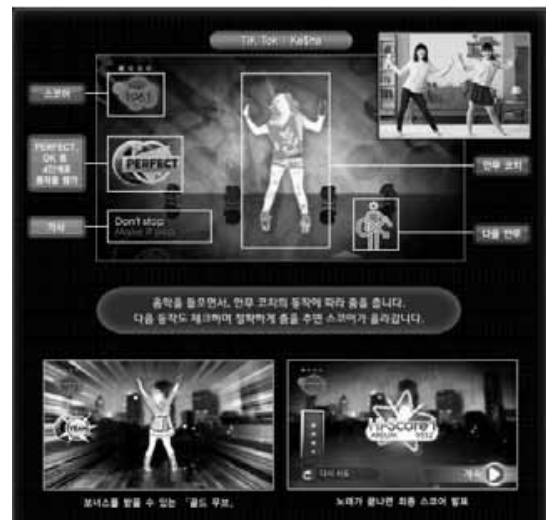

(a)

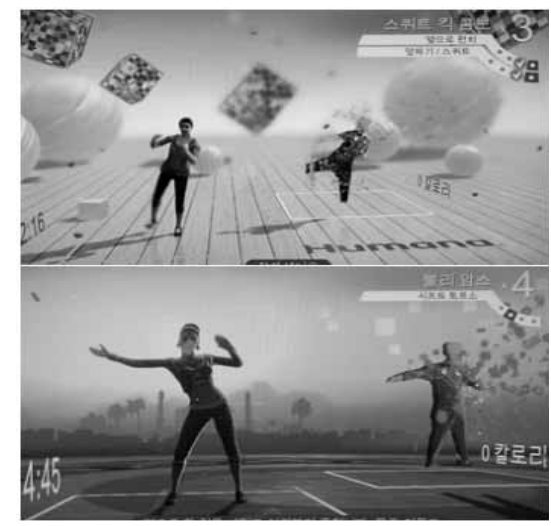

(b)

Fig. 2. Sample scenes of Just Dance2 and Your Shape Software 


\section{3. 제안하는 체감형 콘솔 게임 시스템}

본 논문에서 제안하는 체감형 콘솔 게임은 키넥트가 연결 된 컴퓨터와 노래 및 관절 데이터 등을 관리하는 서버로 구 성이 되어 있다. Fig. 3은 전체 시스템의 구조와 게임 진행 과정을 보여준다.

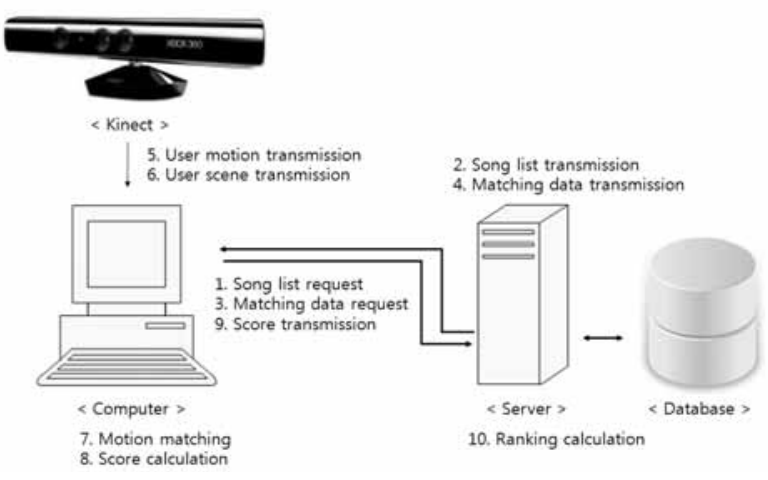

Fig. 3. Overall system structure and game playing process

먼저 컴퓨터는 서버에 노래 목록을 요청하여 전송 받는다. 사용자는 노래 목록 중 플레이 할 노래를 선택한다. 이 때, 컴퓨터는 서버에 해당 노래에 대한 비교 데이터를 요청하여 전송 받는다. 게임이 시작되면 컴퓨터는 비교 동영상과 함께 키넥트로부터 사용자 화면을 전송받아 Fig. 4와 같이 화면에 출력하고 사용자 동작을 검출한다. 그리고 동작 비교 기법을 이용하여 현재 사용자 동작과 비교 데이터의 일치율을 계산 한다. 매 프레임 마다 일치율을 계산하여 30 프레임 중 가장 높은 일치율을 정해진 기준에 따라 키워드 출력 및 사용자에 게 점수를 부여한다. 노래가 끝나면 총점을 서버에 전송하여 해당 총점을 이용하여 랭킹을 산출한다.

본 절에서는 개발한 게임의 자동 업데이트, 동작 저장 및 매칭 기법, 게임 결과 및 랭킹 출력 등에 대하여 설명한다.

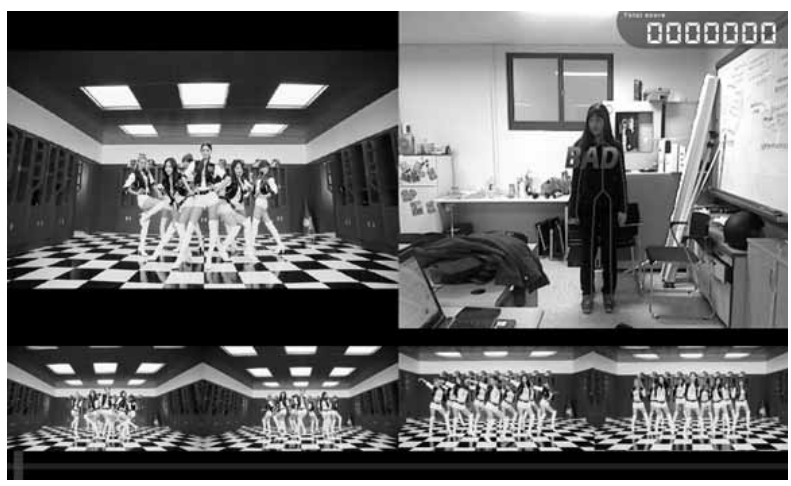

Fig. 4. Playing scene of the presented game

3.1 자동 업데이트 기법

기존 게임들은 $\mathrm{DVD}$ 형태로 출시되기 때문에 업데이트가 불가능하다. 그 점을 보완하여 본 논문에서 개발한 시스템
은 다음과 같은 업데이트 기법을 적용하였다.

파일 서버를 구축하고 게임 런쳐 실행 시 Fig. 5과 같이 사용자 컴퓨터 내 시스템 파일에 대한 존재 유무와 손상을 확인한다. 이 때 이상이 있는 파일이 있을 경우 해당 파일 을 전송하여 최신 데이터를 유지한다. 또한 Fig. 6과 같이 사용자에게 전송상태를 보여준다.

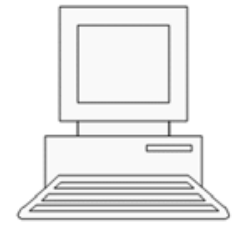

$<$ Computer $>$

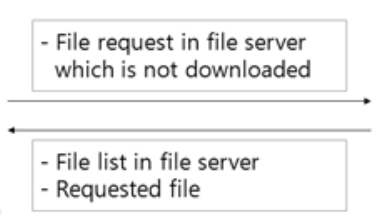

Fig. 5. File transmission process

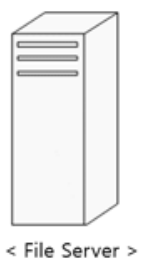

$<$ File Server >

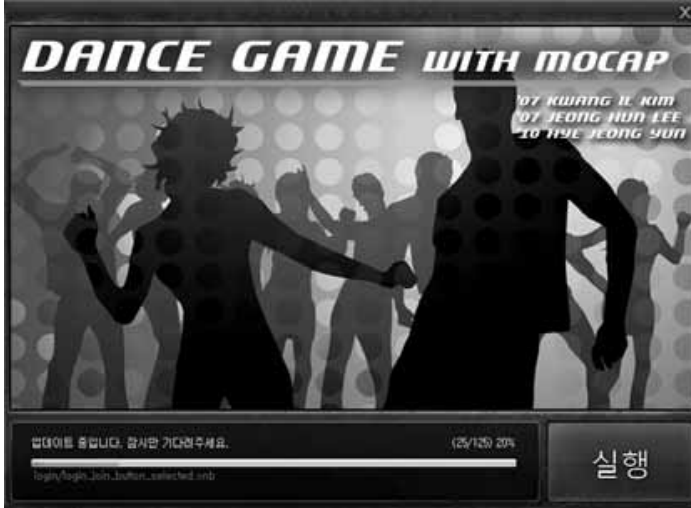

Fig. 6. Launcher screen

\section{2 동작 저장 기법}

제안한 게임에서는 노래 데이터 및 비교 데이터의 추가를 위하여 키넥트로부터 사용자의 동작을 인식하고 해당 동작 을 서버의 데이터베이스에 저장한다. Fig. 7은 동작 저장 과 정을 보여준다. 먼저 Kinect $\mathrm{SDK}$ 를 이용하여 인식된 사용 자의 동작을 가져온다[7]. 해당 동작에서 Fig. 8에 표시된 것

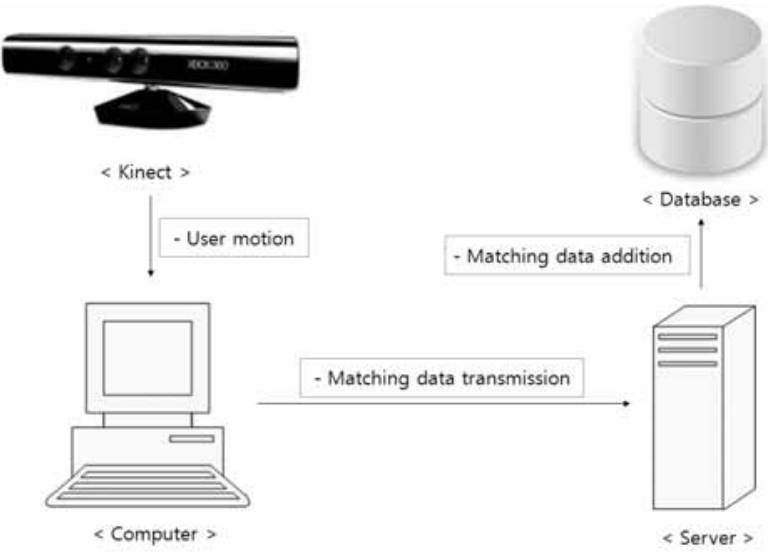

Fig. 7. Motion addition process 
과 같이 (머리-늑골), (늑골-골반), (오른쪽 어깨-오른쪽 팔 꿈치), (오른쪽 팔꿈치-오른쪽 손), (골반-오른쪽 무릎), (오 른쪽 무릎-오른쪽 발), (왼쪽 어깨-왼쪽 팔꿈치), (왼쪽 팔꿈 치-왼쪽 손), (골반-왼쪽 무릎), 및 (왼쪽 무릎-왼쪽 발)의 10 개 관절에 대해 각각 $\mathrm{X}-\mathrm{Y}$ 축, $\mathrm{X}-\mathrm{Z}$ 축의 각도를 계산하여 총 20개 각도 데이터를 서버로 보낸다.

관절간의 각을 구하는 방식은, 예를 들어 (오른쪽 어깨오른쪽 팔꿈치) 각을 구할 때에는 Fig. 9와 같이 두 관절의 차이를 이용하여 삼각형을 만들고, 아크탄젠트 함수를 사용 해 $\mathrm{X}-\mathrm{Y}$ 축 각도(Radian)를 계산한다. $\mathrm{X}-\mathrm{Z}$ 축 각도 또한 같은 방식으로 계산한다.

이와 같은 관절각 데이터를 처리하기 위하여 서버에서는 해당 데이터 프레임 번호를 저장하기 위한 정수형 값 1 개와 20 개의 관절간 각도를 저장하기 위한 실수형 값 20 개로 구 성된 데이터베이스 테이블을 관리한다.

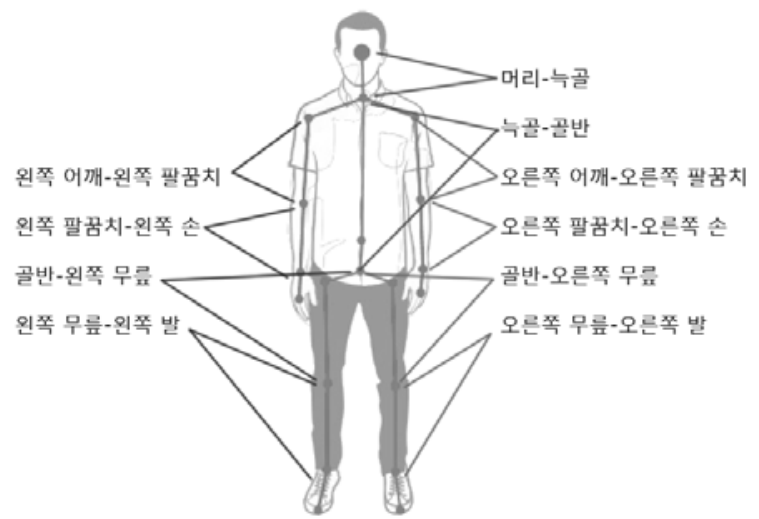

Fig. 8. 10 angle information used for motion matching
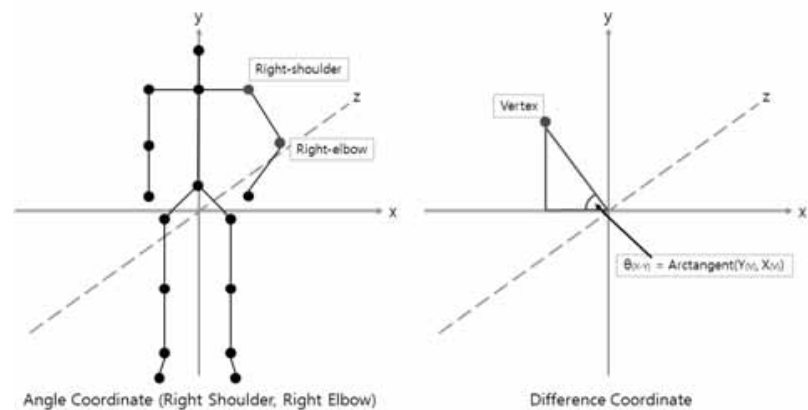

Fig. 9. $X-Y$ and $X-Z$ axis angle calculation between each joint

\section{3 커스텀 데이터 저장 기법}

제안한 게임은 사용자가 직접 자신만의 데이터를 추가하여 플레이할 수 있다. Fig. 10과 같이 저장할 동영상의 배경음악 이름을 컴퓨터 내 노래 중에서 선택 및 입력하고 가수명 및 저장할 동영상의 시간을 입력한다. 녹화 버튼을 선택하여 카 운트다운 후 재생되는 노래에 맞춰 사용자가 춤을 추면 해당 영상은 키넥트를 이용하여 실시간으로 파일에 저장된다.
동시에 키넥트는 깊이 영상처리를 이용하여 사용자를 찾 고, 사용자의 관절들을 Skeleton Stream에 $(\mathrm{X}, \mathrm{Y}, \mathrm{Z})$ 좌표 값으로 저장한다. 저장되어 있는 관절들의 좌표 값들을 이용 하여 동작 저장 기법에서 설명한 것과 같은 방식으로 관절들 간의 각을 계산하고 Skeleton Angles 객체에 누적 저장한 후 녹화가 마무리되면 해당 객체에 저장된 모든 관절 정보를 $\mathrm{DWM}$ 포맷 파일에 저장한다. 동영상 파일과 $\mathrm{DWM}$ 파일은 게임 폴더 내의 컨텐츠 폴더에 저장되고, 저장된 커스텀 데 이터는 시스템 데이터와 같은 방식으로 플레이 할 수 있다.

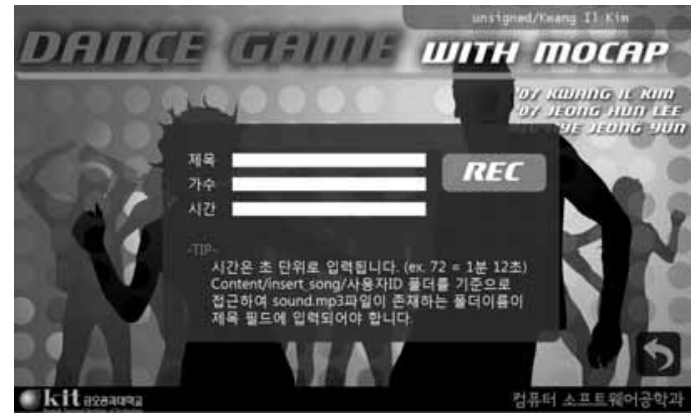

Fig. 10. Information input scene before game recording

\section{4 동작 매칭 기법}

제안한 게임에서는 키넥트를 이용하여 사용자 동작을 인 식하고 해당 동작을 데이터베이스에 미리 저장해둔 비교 데 이터와 비교한다. Fig. 11는 동작 비교 과정을 보여준다.

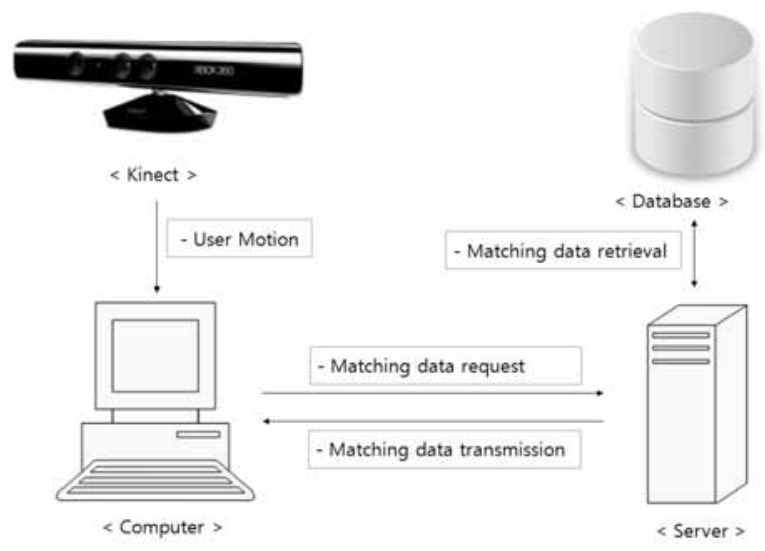

Fig. 11. Motion matching process

먼저 컴퓨터에서 해당 노래 비교 동작을 서버에 요청한 다. 서버는 비교 동작을 데이터베이스에서 검색하여 컴퓨터 로 전송한다. 컴퓨터는 키넥트로부터 인식된 사용자 동작을 가져오고 해당 동작에 대해 동작 저장 기법에서처럼 20개 각도를 계산한다. 마지막으로 현재 사용자 동작의 각도과 비교 데이터의 각도에 대하여 다음 수식과 같이 일치율을 계산한다. 


$$
\text { Matching rate }=\sum_{i=1}^{20} \frac{\left|M_{i}-R_{i}\right|}{2 \pi} \cdot 100
$$

$M i$ 는 현재 사용자 동작에 대하여 측정된 관절 각도이고, $R i$ 는 데이터베이스에 저장되어 있는 비교 데이터의 관절 각 도이다. 두 각도 사이의 차이값에 대하여 절대값을 취한 후 180 도를 기준으로 하여 해당 관절의 동일성 퍼센티지를 구 한다. 총 20 개의 관절 각도에 대하여 동일성 퍼센티지의 평 균을 계산할 수 있고 이를 일치율로 사용하였다.

매 프레임마다 일치율을 계산하여 30프레임 중 가장 높은 일치율을 측정해 Table 2 의 기준에 따라 키워드 출력 및 점 수를 부여한다. 특히 동작 매칭 기법을 이용하여 사용자 현 재 동작이 저장된 데이터와 다를 경우 실시간으로 화면을 통해 알려준다. Fig. 12 의 왼손 부분과 같이 사용자 동작이 비교 데이터와 다를 경우 이를 틀린 동작으로 인식한다. 이 때 인식하는 기준은 비교 데이터가 머리-목, 골반-양쪽무릎, 양쪽무릎-양쪽발목일 경우 전 프레임과 거의 비슷하므로 $80 \%$ 이하, 양쪽어깨-양쪽팔꿈치, 양쪽팔꿈치-양쪽손목일 경 우 전 프레임과 차이 날 확률이 높으므로 $50 \%$ 이하로 정하 여 비교 데이터를 화면에 출력해준다. 또한 한 노래마다 틀 린 부분이 연속 30 프레임 이상일 경우 동영상을 저장하여 틀린 부분 동영상을 이어서 사용자 컴퓨터에 저장한다.

Table 2. Keyword and score depending on matching rate

\begin{tabular}{c|c|c}
\hline Matching rate & Keyword & Score \\
\hline over $95 \%$ & Perfect & 10,000 \\
\hline over $85 \%$ & Excellent & 8,000 \\
\hline over $75 \%$ & Good & 3,000 \\
\hline over $65 \%$ & Not Bad & 1,000 \\
\hline under $65 \%$ & Bad & 0 \\
\hline
\end{tabular}

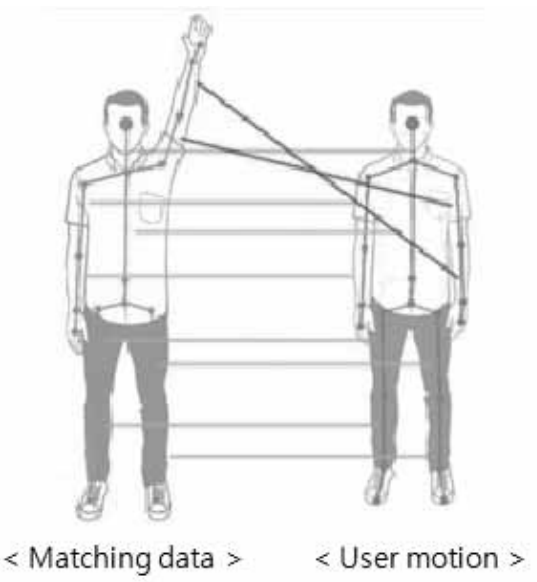

Fig. 12. Motion matching technique

\section{5 게임 결과 출력 및 랭킹 부여 기법}

Fig. 13 는 게임 결과와 그 결과에 대한 랭킹 부여 화면이 다. 먼저 컴퓨터는 곡의 시간에 비례하여 사용자가 획득한 총 점수에 대한 플레이 등급을 계산한다. 그리고 총 점수를 서버에 보내 해당 점수에 대한 랭킹을 계산한다. 만약 계산 된 랭킹이 출력 랭킹 범위 내에 있으면 서버에 새로운 랭킹 데이터를 추가한다. 마지막으로 서버로부터 해당 곡의 랭커 의 정보를 받아 게임 결과를 출력한다.

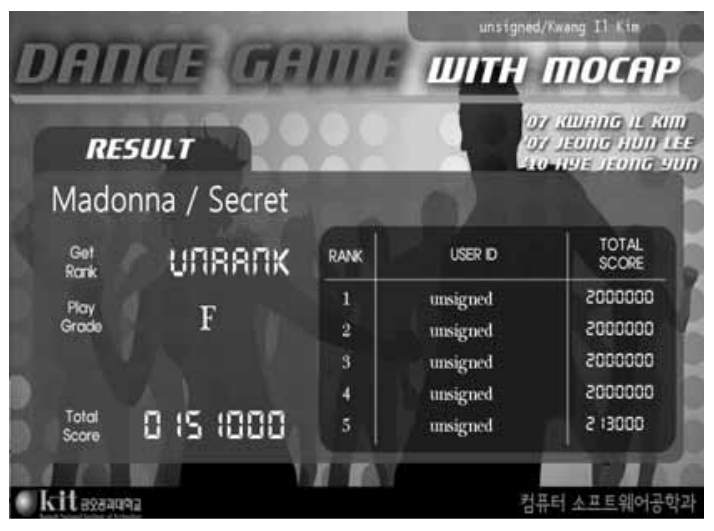

Fig. 13. Game result and score scene

\section{6 사용자의 편의를 위한 기타 설정}

제안하는 게임에서는 사용자에게 안무를 쉽게 익히기 위한 편의성을 제공하기 위해 반복모드를 지원한다. 설정 창에서 반복모드를 선택한 후 반복할 시간을 선택하면 사용자가 다 음영상으로 넘어갈 때까지 영상이 반복된다. 또한 Fig. 4와 같이 좌측하단부터 1 초, 2 초, 3 초, 및 4 초 후의 영상을 미리 출력하므로 사용자가 다음 동작을 쉽게 알 수 있도록 한다.

사용자가 자리를 비울 시(스켈레톤 미인식시)에는 게임이 일시 정지되며, 여러 명의 스켈레톤이 인식될 시에는 깊이 가 가장 가까운 스켈레톤을 인식하여 게임을 진행한다.

\section{4. 실험 결과}

본 논문에서 제안하는 동작 인식 댄스 게임을 실행한 화 면을 Fig. 14에 제시하였다. 게임 메뉴 선택, 노래 선택, 게 임 옵션 선택, 게임 플레이 장면들을 확인할 수 있고, 실제 자신의 모습이 제시되고, 앞으로의 제시될 장면에 대한 출 력을 통하여 게임의 흥미가 높음을 확인할 수 있다.

제안하는 게임의 성능을 평가하기 위하여 CPU Intel i5-3 세대, RAM 8GB, Intel $\mathrm{HD} 4000 \mathrm{VGA}$ 가 장착된 컴퓨터에서 동작 매칭에 대한 수행 속도를 측정하였다. 다양한 동영상 에 대하여 약 323 초 동안 게임을 재생하였고, 총 6,540 프레 임에 대하여 동작 매칭을 수행하였다. 이 시간 동안 동작 매칭에 약 $568 \mathrm{msec}$ 가 소요되었고 약 1프레임 당 0.086 


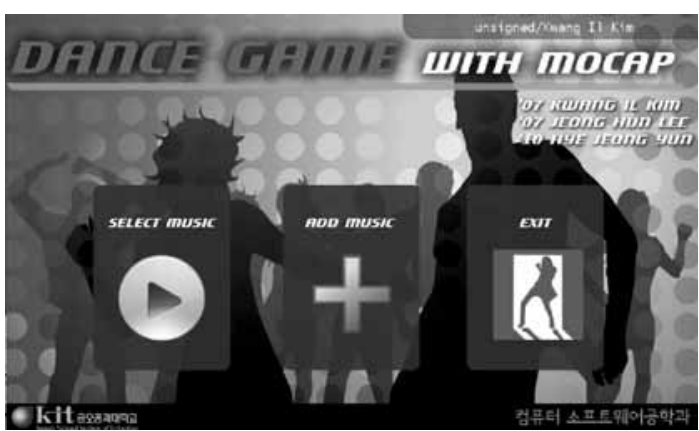

(a) Game menu selection

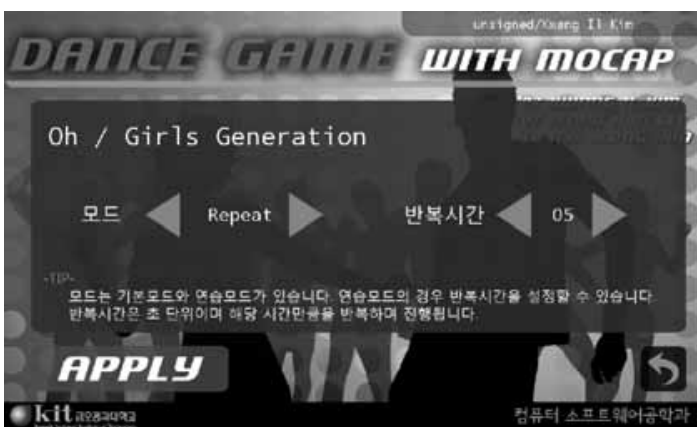

(c) Game option selection

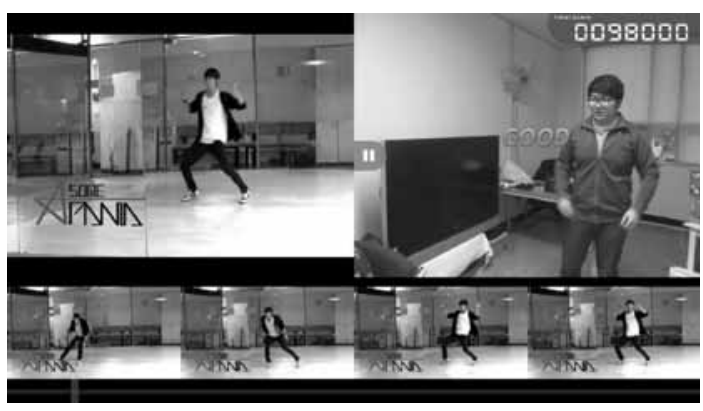

(e) Game playing scene

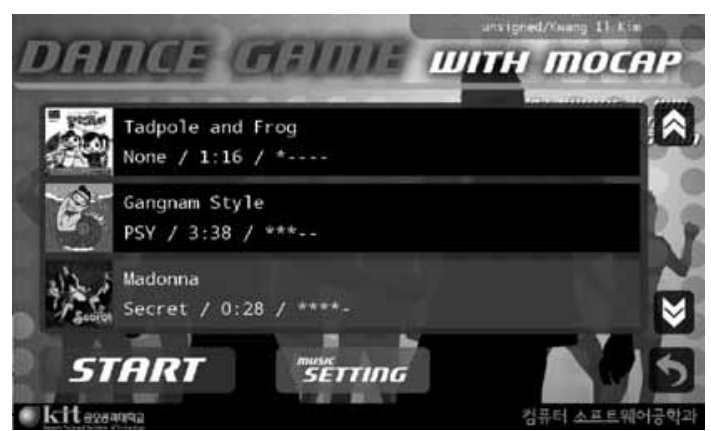

(b) Song selection

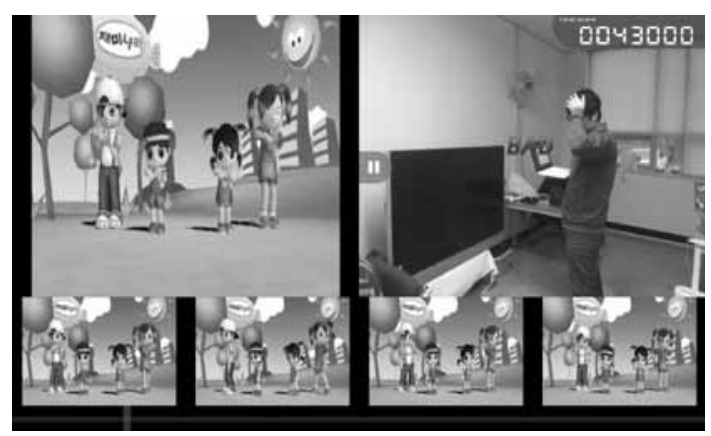

(d) Game playing scene

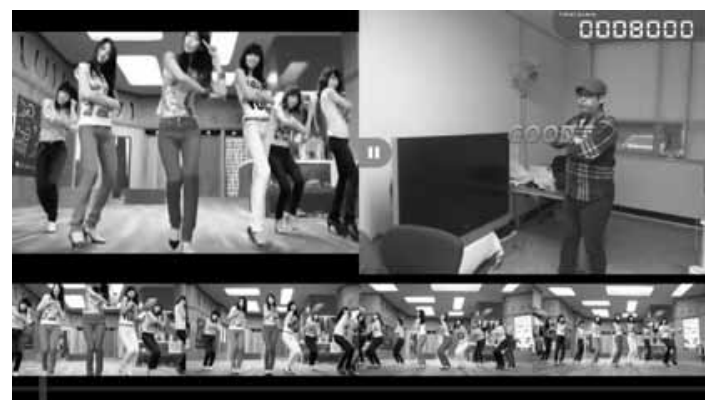

(f) Game playing scene

Fig. 14. Example scenes of playing the presented experience dance game

$\mathrm{msec}$ 정도가 소요되어 동작 매칭이 빠르게 처리되는 것을 확인할 수 있었다.

\section{1 동작 매칭 횟수 분석}

본 논문에서 제안하는 게임을 닌텐도 Wii의 "Just Dance2" 게임과 동작 비교 횟수, 비교 데이터 수를 기준으 로 비교하였다. 다만, Just Dance2 게임의 경우 내부 알고리 즘 등 정보가 공개되어 있지 않기 때문에 하드웨어 정보를 조사하여 알고리즘을 추정하였다. 게임에 사용되는 wii 리모 콘은 내부에 3 축의 가속도와 기울기를 인식할 수 있는 $\mathrm{ADXI} 330$ 가속도계를 탑재하고 있다[8][9]. 또한 PixArt 광학 센서를 탑재하고 있어서 리모콘이 어디를 가리키고 있는지 감지할 수 있다[10]. 이러한 정보를 확인한 결과 Just Dance2 게임은 리모콘이 가리키는 위치 변화 및 가속도를 초당 1 회 측정하
여 점수를 매김을 유추할 수 있다. 초당 비교하는 데이터의 묶음을 키 프레임이라고 표현하자면, Table 3과 같이 Just Dance2는 키 프레임 당 2개의 비교 데이터를 사용한다. 즉, 키 프레임 수*2개 비교 데이터를 사용하고, 제안한 게임은 곡의 시간(초) $* 20$ 개(각도)의 비교 데이터를 사용한다.

키 프레임의 수는 실제 영상 마다 다르므로 곡의 시간 (초)를 180 초로 가정하면 Table 4와 같은 결과를 얻을 수 있다. Just Dance2는 총 360개의 비교 데이터를 사용하고, 본 논문에서는 3,600 개의 비교 데이터를 사용한다. 이를 통 하여 제안하는 게임이 기존 시스템의 동작 비교보다 10 배 이상의 많은 비교 수행을 통하여 동작 매칭의 정확도를 향 상하였음을 알 수 있다. 
Table 3. Matching data comparison measure of the previous and presented game

\begin{tabular}{c|c|c}
\hline & Previous game & Presented game \\
\hline \# of motion matching & \# of key frame & playing time $(\mathrm{sec})$ \\
\hline \# of matching data & $2 /($ key frame) & $20 / \mathrm{sec}$ \\
\hline Total \# of matching data & \# of key frame*2(ea) & playing time*20(ea) \\
\hline
\end{tabular}

Table 4. Number of matching data comparison based on the assumption

\begin{tabular}{c|c|c}
\hline & Previous game & Presented game \\
\hline \# of motion matching & 180 & 180 \\
\hline \# of matching data & $2 /($ key frame) & $20 / \mathrm{sec}$ \\
\hline Total \# of matching data & 360 & 3,600 \\
\hline
\end{tabular}

\section{2 인터페이스 실험 결과}

기존의 시스템은 사용자 자신의 모습을 $\mathrm{NPC}$ 아바타로 대체하여 화면에 보여준다. 본 논문에서는 사용자 자신의 모습을 화면에 그대로 보여줌으로써 사용자가 자신의 모습 을 확인할 수 있고, 사용자들에게 더 흥미를 끌 수 있다.

본 실험에서는 2012년 공학교육 페스티벌(전국대회)와 금 오공과대학교 2012 Engineering Fair 등 전시회에서 참관객 들에게 원하는 시스템을 이용할 수 있도록 한 뒤 해당 사용 자에게 0 점에서 10 점 사이의 점수를 받아 평균점수를 이용 하여 호응도를 분석하였다. Table 5는 기존의 시스템과 본 논문의 시스템을 전시하여 이용한 횟수 및 평점을 도표화 한 것이다.

Table 5. Qualitative favor analysis of the previous and presented game

\begin{tabular}{c|c|c|c}
\hline & Nintendo Wii & MS XBOX360 & Presented game \\
\hline \# of users & 22 & 72 & 127 \\
\hline \# of usage & 27 & 78 & 154 \\
\hline Average score(10) & 6.58 & 7.89 & 9.24 \\
\hline
\end{tabular}

호응도 분석 결과를 보면, 제안하는 게임은 닌텐도 Wii보 다 약 6 배 많은 이용횟수와 1.4 배 높은 평점을 받았다. MS $\mathrm{XBOX} 360$ 보다 약 2 배 많은 이용횟수와 1.2 배 높은 평점을 받았다. 이로써 본 논문에서처럼 사용자 화면을 보여주는 것은 사용자들에게 호기심과 흥미를 유도하고 게임의 재미 를 더 한다는 것을 알 수 있다.

\section{5. 결 론}

콘솔 게임은 게임 시장에서 가장 높은 비율을 차지한다. 그 중에서도 체감형 콘솔 게임은 새로운 메커니즘을 형성하
며 독자적인 시장을 구축해왔다. 하지만, 기존 콘솔 게임 소 프트웨어는 쉽게 싫증을 느낄 수 있고, 높은 비용을 요구 하여 사용자에게 부담을 준다.

본 논문에서는 저렴하고 쉽게 싫증나지 않도록 지속적 업 데이트가 가능한 체감형 게임을 제안하였다. 이는 지속적으 로 다양한 콘텐츠를 사용자에게 제공할 수 있도록 한다. 특 히 기존 콘솔 댄스게임에서는 자신의 모습을 볼 수 없을 뿐 만 아니라 지정한 동작만을 비교하는 반면 제안하는 댄스게 임에서는 자신의 모습을 확인가능하며, 매 초 마다 전체 동 작을 비교해 높은 정확도와 흥미를 부여한다. 이와 같은 게 임을 이용하여 사용자의 스트레스 해소 및 건강 향상 효과 를 기대할 수 있다. 그러나 제안한 게임의 상용화를 위해서 는 최적화, 사용자 인터페이스 향상, 효율적인 데이터 관리 방안 수립 등의 보완이 필요하다.

현재 개발한 기술은 단순히 게임에만 적용하는 것이 아니 라 다양한 교육용 프로그램에도 활용이 가능하다. 최근 $\mathrm{K}-\mathrm{POP}$ 열풍으로 인하여 방송용 춤에 대한 관심이 높아지 고 있으며, 개발한 기술을 적용하여 실제 강사의 동작을 비 교 데이터를 입력하고, 학습자가 춤을 추는 과정에서 강사 의 비교 데이터와 정확도에 대한 비교를 통하여 올바른 모 습에 대한 교정을 수행할 수 있다. 또한 요가 등의 자세에 대한 교정에도 활용이 가능하다.

\section{참 고 문 헌}

[1] Korea Creative Contents Agency (KOCCA), "2012 Foreign Contents Market Trend Survey (The First Half Year)", KOCCA Research Report, 2012, pp. 85-92.

[2] J. Kang, "The Share and Future of World Game Market," KOCCA Statistics Briefing, vol. 13(13), 2013.

[3] Entertainment Software Association (ESA), "The 2013 Essential Facts About the Computer and Video Game Industry," Annual Research Reports, 2013.

[4] Korea Creative Contents Agency (KOCCA), "Content Technology (CT) In-Depth Report Vol. 5: Technology and Market Trend of Experience Console Game”, KOCCA Research Report, 2010.

[5] Y. Mehdi, "Xbox Beyond the Box", The Official Microsoft Blog in TechNet Blogs, May 29, 2012.

[6] Nintendo Homepage, "http://www.nintendo.co.kr/".

[7] Microsoft Kinect SDK, "http://www.microsoft.com/en-us/ kinectforwindows/develop/".

[8] Wii の概要 コントローラ, "http://www.nintendo.co.jp/event/e3_ 2006/wii/controller.html”.

[9] H. Wisniowski, "Analog Devices And Nintendo Collaboration Drives Video Game Innovation With iMEMS Motion Signal Processing Technology," Analog Devices, Inc., (http://www. analog.com/en/press-release/May_09_2006_ADI_Nintendo_ 
Collaborat-ion/ press.html), May 9, 2006.

[10] K. Castaneda, "Nintendo and PixArt Team Up," Nintendo World Report, May 13, 2006.

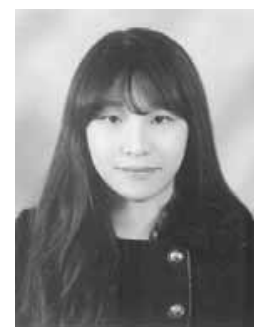

\section{윤 혜 정}

e-mail : hj4680@nate.com

2013년 금오공과대학교 컴퓨터소프트웨어 공학과 재학중

관심분야 : 영상처리, 그래픽스 등

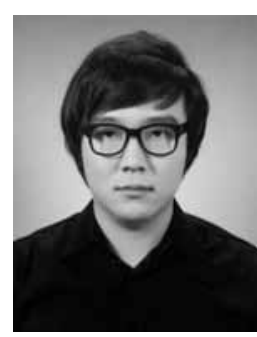

\section{김 광 일}

e-mail : disappoint00@naver.com

2013년 금오공과대학교 컴퓨터소프트웨어 공학과 재학중

관심분야 : 모바일 및 게임개발, 알고리즘 연구 등

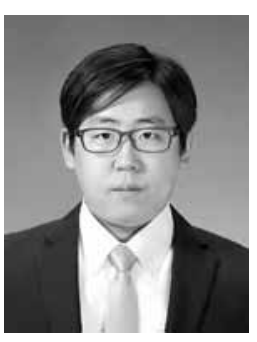

이 정 훈

e-mail : wkwjsrt0120@naver.com

2013년 금오공과대학교 컴퓨터소프트웨어 공학과 재학중

관심분야 : 모바일, 영상처리, 인공지능 등

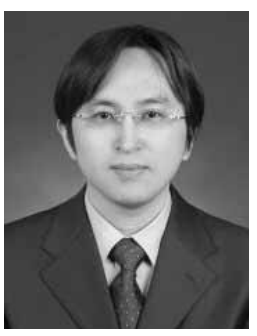

\section{이 해 연}

e-mail : haeyeoun.lee@kumoh.ac.kr

1997년 성균관대학교 정보공학과(학사)

1999년 한국과학기술원 전산학과(공학석사)

2006년 한국과학기술원 전자전산학과 전 산학전공(공학박사)

2001년 2006년 (주)쎄트렉아이 선임연구원

2006년 2007년 코넬대학교 박사후연구원

2008년 현 재 국립금오공과대학교 컴퓨터소프트웨어공학과 교수 관심분야 : 멀티미디어, 영상처리, 콘텐츠보안, 디지털워터마킹 